\title{
FAILURE ANALYSIS FOR HIGH STRESS GEAR
}

\author{
R. I. Goher ${ }^{1}$, B. S. Azzam² \& M. M. Abdrabou ${ }^{3}$
}

Abstract-Gear failure is one of the most headache problems in the industry particularly when it is occurred during the critical operation season of the industrial systems. One of these situations was occurred during the season of sugar industry. The gear was manufactured from carburized steel DIN standard No.1.6587 (18CrNiMo7-6). The gear, module is 5.08 mm, pressure angle is $20^{\circ}$, No of teeth is 16 , width is $85 \mathrm{~mm}$ and helix angle is $8.5^{\circ}$ Right with mating gear No of teeth is 70 teeth. The failure was occurred within 1 month of continuous operation. The gear is driven by $315 \mathrm{~kW}$ motor at $1450 \mathrm{rpm}$. A visual investigation has been carried out, a set of photos were taken and the working conditions were reviewed. The visual investigation showed that the pinion has undergone some broken teeth at the pinion and pettings in the mating gear. The operating conditions have been revised during consecutive intervals of operation. The design data has been reviewed according to standard gear design recommendations. Material analysis and micro hardness measurements followed by a micro structure have been also investigated. The micro hardness survey through the teeth tips and roots revealed that the carburization case depth was not adapted with the standards recommendations. The case depth was, $2.3 \mathrm{~mm}$ at teeth tip and $1 \mathrm{~mm}$ at teeth root, and that is not suitable and more than the standards recommendations to the gears of module $5.08 \mathbf{~ m m}$. The micro hardness measurements and micro structure ensured that the case hardness at gear tips was larger than the standards values and not conformed with the module which resulted a full hardening at the teeth tip portion make it brittle. This refers to an excessive carburizing time. Also the big difference between case depth at the teeth, top and the root, occurred due to bad circulation of the salt bath around the pinion. Under, the high cyclic bending stress $\sigma_{F}=400 \mathrm{~N} / \mathrm{mm}^{2}$ and contact stress $\sigma_{H}=1300 \mathrm{~N} / \mathrm{mm}^{2}$ at the pinion teeth while the design values are $259 \mathrm{~N} / \mathrm{mm}^{2}, 723 \mathrm{~N} / \mathrm{mm}^{2}$ respectively so the teeth started to fail. Thick layer of the carburized case may lead to more probable brittle case at teeth tips which lead to cracks initiation. Therefore, it is recommended to select the carburizing parameters matching with standards recommendations of the carburizing layer with correct case depth and maintaining its thickness difference at both the teeth tips and roots at minimum as possible. Also high stress required to redesign the gearbox again for suitable stresses levels according design standards.

Keywords - Gear failure, Sugar industry, high stress gears, Case depth, Hardness, 18CrNiMo7-6.

\section{INTRODUCTION}

Gear failure is one of the most serious problems causing a headache to gears designers, manufacturers and users. The industrial processes do not need an unplanned shut down due to any reasons because it cost a lot of money and waste of time and effort. Gear failure have many reasons to occur; it may happen due to a lot of error sources in gear process production such as: design, manufacturing, heat treatment, maintenance or random so, the problem of gear failure must be analyzed, investigated, and clearly solved for avoiding its bad effects in the operation.

The present case investigates a pinion gear failure in sugar industry which was subjected to a high stress due to, high power drive motor $315 \mathrm{kw}$, single stage reduction of 16/70, module 5.08 and width $85 \mathrm{~mm}$. the gear box is driving a circulation fan which is critical in the industry process. This circulation fan must work $24 \mathrm{hrs} /$ day. The environmental and operating conditions were reviewed carefully searching for corrosion, erosion or overload causes. The routine maintenance was carried out. Material selection and heat treatment specifications were analyzed and compared to gear standard design recommendations. Visual inspection and a set of photos were taken for documenting the failure case as shown in figures $(1,2$, 3). Micro hardness survey was carried out to the teeth and the area between teeth at the root sections. Also the gear microstructure was investigated looking for the microstructure and compare it with the target microstructure of the standards. The contact stress and bending stress on the teeth are calculated regarding the operating conditions. The gear design criteria were reviewed concerning the design standards procedures and recommendations. The results of the above investigations were discussed concerning the design and standards requirements. Also a comparison with other works was done. Finally conclusion and recommendations were drawn.

\section{LITERATURE SURVEY}

For avoiding failure; the gear loads and stresses must be calculated correctly and design parameters such as the dimensions, accuracy, material, heat treatment and finishing specifications to be selected according to the standards and design guidance

\footnotetext{
${ }^{1}$ Phd student, Department of Mechanical Design and Production Engineering, Cairo University Faculty of Engineering, Giza, Giza, Egypt

2 Professor, Department of Mechanical Design and Production Engineering, Cairo University Faculty of Engineering, Giza, Giza, Egypt

${ }^{3}$ Professor, Department of Mechanical Design and Production Engineering, Cairo University Faculty of Engineering, Giza, Giza, Egypt
} 
literatures. The gear design specifications are identified, applied and reviewed before it launched. Also manufacturing specifications should be selected accurately for verifying the design target data.

Rossino et al [1] found that the surface contact fatigue failure was resulted from the excessive carburizing case depth which led to an intergranular carbon-rich brittle cementite. This causes a crack initiation when contact stress is applied with cyclic load followed by crack propagation until intergranular fracture occurred.

Saber [2] observed that although the material and the heat treatment have satisfied the recommended values but it was noticed that the pinion which subjected to more cyclic load had case hardness less than the gear. Pinion is subjected to more cyclic loads. So, the hardness selection may be done for safety or for replacing the smaller one at failure but under fatigue, the pinion teeth were failed and the broken fragments start to initiate pitting and cracks at both pinion and gear teeth.

Starzhinskii et al [3] stated that, to increase the gear surface life, there are many parameters must be controlled for ensuring optimum; tempered martensite microstructure, carburizing depth, proper hardness and absence of; micro-cracks, decarburization, corrosion, and machining defects.

Tobie et al [4] had shown that the case hardness depth can Influencing both bending and surface (contact) load capacity but in different manners. Maximum load capacity is achieved for an optimum value of case depth, but optimum values for maximum tooth root bending strength and pitting resistance of gear not necessarily be at the same parameters. An unfavorable case depth, smaller or larger than the optimum, leaded to a reduction of attainable load capacity.

Netpu and Srichandr [5] found that the gear teeth stress could cause failure if it increases the allowable design strength of the gear materials. So the contact stress started pitting or/and cracks on the surface, which developed to fatigue cracks causing cracks propagation till failure. Also failure occurred due to the excessive stress when the driving power was increased from $300 \mathrm{~kW}$ to $600 \mathrm{~kW}$ without re-evaluate the stresses.

Yuruts and Aleksandrov [6] had stated that the micro mechanism of fatigue failure is depending on the fatigue stress amplitude.

Koshy and Taji [7] concluded that high stresses initiated cracks at the tooth root because this section had the maximum tensile stress.

Fernandes and Mcduling [8] indicated that contact fatigue damage would first had occurred in the dedendum of the smaller gear suffered more revolutions, and therefore each tooth will experience a larger number of stress cycles. So, it is recommended that the smaller gear must be harder than the mating gear.

\section{PROBLEM DEFINITION}

Sugar industry is a seasonal industry so, the production line components must be stable and reliable through the production season to avoid a lot of loss. In the present case, a circulation fan gearbox with the following data:

Electric motor power is $315 \mathrm{kw}$, The input speed is $1450 \mathrm{rpm}$, The reduction ratio is 1:4.375, Single stage 16/70.

Operation 24 hrs, Equipped with oil cooling system, The structure is rigid.

The gears teeth design data were reviewed from the design drawing. The gears material was carburized steel DIN standard No.1.6587 (18CrNiMo7-6) and heat treatment specifications were:

Case hardening depth: $1.2-1.4 \mathrm{~mm}$

Case hardness $\mathrm{Hv} 30=700-720 \mathrm{~kg} / \mathrm{mm} 2$

Tempering $2 \mathrm{hrs}$ at $200 \mathrm{Co}$

The geometrical design data were summarized in the following table:

Table (1) Geometrical design data

\begin{tabular}{|l|l|l|}
\hline Parameter & Pinion & Gear \\
\hline No of teeth & 16 & 70 \\
\hline Module & \multicolumn{2}{|c|}{5.08} \\
\hline Pressure angle & \multicolumn{2}{|c|}{$20^{\circ}$} \\
\hline Helix angle displacement & $8.5^{\circ} \mathrm{R}$ & $8.5^{\circ} \mathrm{L}$ \\
\hline $\begin{array}{l}\text { Profile } \\
\text { factor }\end{array}$ & & 0.541 \\
\hline Profile displacement & 2.5 & 2.75 \\
\hline Tip diameter & 97.34 & 375.3 \\
\hline Pitch diameter & 82.182 & 359.55 \\
\hline Root diameter & 73.67 & 351.23 \\
\hline Spandistance no of teeth & 3 & 9 \\
\hline Span distance & 40.38 & 134.39 \\
\hline Center distance & 226 & \\
\hline
\end{tabular}

The gear box worked for 1 month and failure was occurred in the pinion gear as shown in the pictures of figures $(1,2,3)$. The failure was studied to discover the failure reasons to avoid them in the future. Failure analysis for that failed gears showed that 
these failures may occurred due to errors of: design, manufacturing, heat treatment, assembly, overload, vibration, maintenance or/and random effects.

The investigation procedure was surveying the assembly, operation and maintenance of the gearbox. Also, the environment was surveyed looking for dust, heat or corrosion sources. The operating conditions also reviewed for finding any overloads.

Material selection was considered and heat treatment specifications were reviewed. The heat treatment cycle parameters were also checked. The micro-hardness measurements survey for the teeth sections and also at the teeth roots at the area between teeth. The microstructure investigations were applied to the teeth and the area between teeth. The results of the previous steps were discussed and conclusions are withdrawn.

\section{THE RESEARCH METHODOLOGY}

The procedure followed in this paper for analyzing the present case failure can be summarized in a set of steps [9, 10, 11] such as:

- Observe visually the failure gears

- $\quad$ Review the gears' manufacturing data

- $\quad$ Check the assembly procedure

- $\quad$ Analyze the working conditions

- Investigate the hardness and the case depth

- Investigate the gears microstructure

- Compare the results of the original gear and the manufactured one

- Compare the results of both the original and manufactured gears with the standards specs.

- Then the failure causes can be carefully identified and recommendations can be given to avoid the future failures.

- Stress analysis review for the gears loading rates concerning bending and contact stresses following the metric AGMA procedure.

\section{OBSERVATIONS AND REVIEW}

The visual observation of the pinion gear after failure had shown that many teeth were broken at the tip section of the teeth and pitting was noticed through the teeth. see figures $(1,2,3)$. Notice that most of pinion broken teeth at the tip.

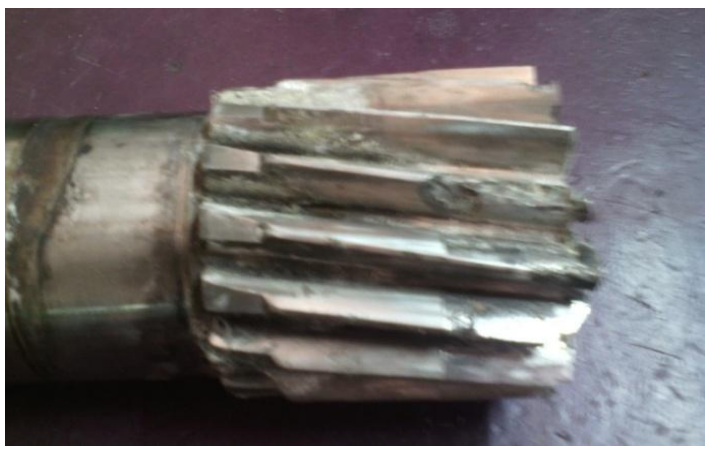

Fig. (1) Pinion gear teeth failure

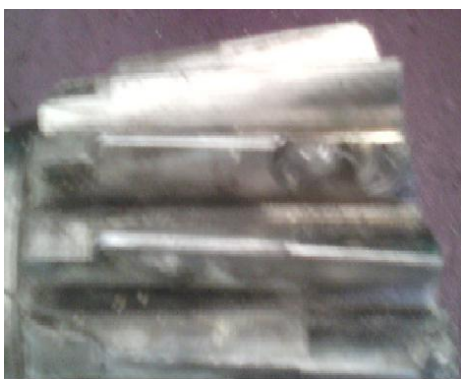

Fig. (3) Pinion gear pitting and failure

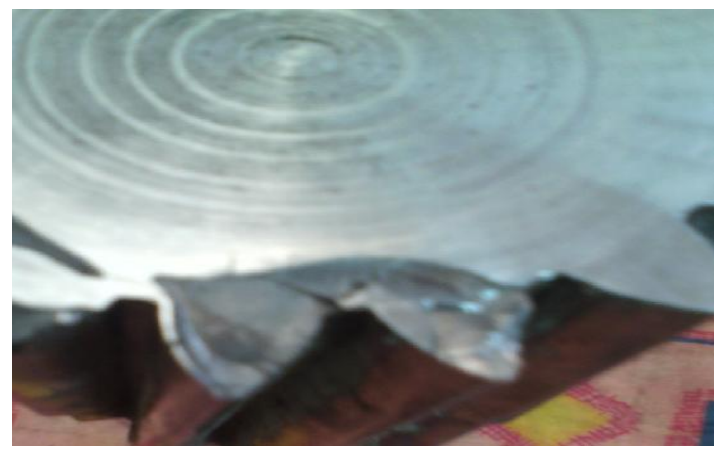

Fig. (2) Pinion gear section failure

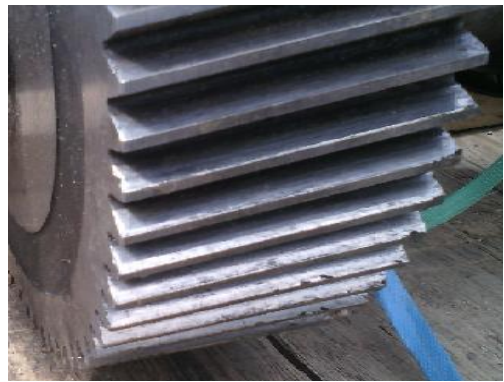

Fig. (4) mating gear teeth pitting

The mating gear teeth had pitting as shown in figure (4) but no complete tooth was broken.

By surveying the operating conditions, there were not any abnormal conditions such as overload sources, excessive heat, shocks or vibration. The gearbox cooling system was working properly. It was noticed that no assembly faults or misalignment and neither sources of abrasion nor sources of corrosion were found.

The design data for the pinion and the gear were reviewed compared to the actual gears data and it were satisfied. 


\section{INVESTIGATION}

The laboratory investigations were carried out which included: material analysis and micro hardness measurement survey across the teeth and the root between teeth followed by a microstructure scan. The following subclasses will show the results of the investigations.

\subsection{Material Analysis}

The spectra and chemical analysis results ensured that the material was confirmed to the German Standard (DIN 1.6587) (18CrNiMo7-6) for both pinion and gear.

\subsection{Hardness Analysis}

A micro hardness $\mathrm{HV}_{0.1} \mathrm{~kg}\left(\mathrm{~kg}_{\mathrm{f}} / \mathrm{mm}^{2}\right)$ test was carried out for pinion through both the teeth section and the area between teeth at the root at which has the maximum bending stress position. The results were then tabulated and presented in the following table (table 2) and figure (5) which show the measured data of the pinion gear.

Table (2) Hardness values through the gear tooth sections for the gear

\begin{tabular}{|c|c|c|}
\hline & $\begin{array}{c}\text { On tooth } \\
\text { surface }\end{array}$ & $\begin{array}{c}\text { Between teeth } \\
\text { roots }\end{array}$ \\
\hline $\begin{array}{c}\text { Depth } \\
(\mu \mathrm{m})\end{array}$ & $\mathrm{HV}_{0.1}\left(\mathrm{~kg} / \mathrm{mm}^{2}\right)$ & $\mathrm{HV}_{0.1}\left(\mathrm{~kg} / \mathrm{mm}^{2}\right)$ \\
\hline 20 & 715 & 664 \\
100 & 697 & 657 \\
200 & 689 & 641 \\
300 & 689 & 619 \\
500 & 672 & 585 \\
600 & 657 & - \\
700 & - & 553 \\
800 & 649 & - \\
1000 & 626 & 530 \\
1100 & - & 503 \\
1200 & 616 & 492 \\
1500 & 598 & \\
1700 & 578 & \\
2000 & 530 & \\
2300 & 513 & \\
2400 & 497 & \\
\hline \multicolumn{2}{|c|}{ Teeth core hardness $\mathrm{Hv}_{0.1}=401 \mathrm{~kg} / \mathrm{mm}^{2}$} \\
\hline
\end{tabular}

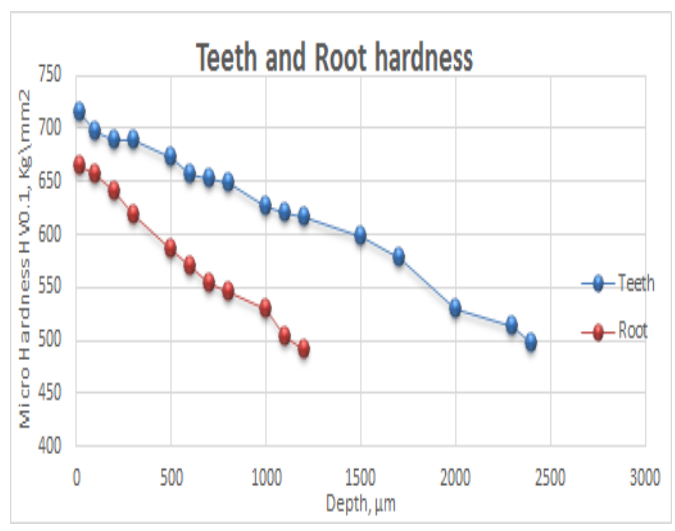

Fig. (5) Pinion gear micro-hardness

The surface hardness HV0.1 of the Gear $=715 \mathrm{Kg} / \mathrm{mm}^{2}$, while the core hardness of the original gear $=401 \mathrm{Kg} / \mathrm{mm}{ }^{2}$. The case depth on the teeth tip of the original gear $=2.3 \mathrm{~mm}$, while the case depth at the teeth root $=1.05 \mathrm{~mm}$ The effective carburizing depth is considered at HRc=50 or HV= 513 (Kozlovskil et al [12]).

\subsection{The Microstructure}

Optical microscope with X500 magnification power was used in investigating the microstructure; Nital Etching 2\% of the specimen. The microstructure of the pinion gear at the case of the teeth are shown in figures (6). 


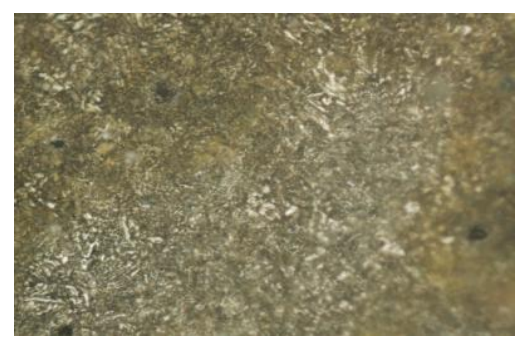

Figure (6) shows tempered martensite with small amount of retained austenite.

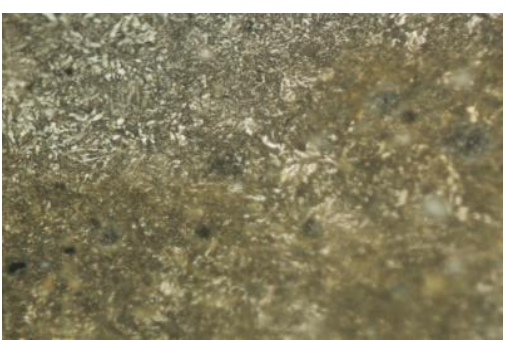

Fig. (7) Pinion gear teeth root microstructure

The microstructure which reveals small amount of martensite; black points in the microstructure.

The microstructure of the manufactured gears, as shown in figure (7) at teeth root reveals an amount of tempered martensite with small amount of retained austenite.

\subsection{Stress Analysis}

Many standards, books and researchers $[13,14,15,16]$ worked in the area of gears stress analysis such as ISO 6336, DIN 3990 and AGMA 2101-C95 (metric system). The followed procedures are almost similar. The present study uses stress analysis based on AGMA standards [13, 14].

There are mainly five equations controlling the design of bending and contact stresses applied to the gear tooth beside the tangential force equations and a set of constants are determined according to the case study operating conditions, geometry, loading, heat treatment, materials, reliability and safety.

The following equations are presenting the general stresses to the gear tooth.

1- The contact stress equation is:

2- Tangential transmitted force equation is:

3- Allowable design stress is:

4- Bending stress equation is:

5- Allowable bending stress equation is:

Where:

$\sigma_{H}$ is contact stress, $\mathrm{N} / \mathrm{mm}^{2}$

$\sigma_{H P}$ is allowable contact stress, $\mathrm{N} / \mathrm{mm}^{2}$

$\mathrm{Z}_{\mathrm{E}}$ is elastic coefficient $\left[\mathrm{N} / \mathrm{mm}^{2}\right]^{0.5}$

$\mathrm{F}_{\mathrm{t}}$ is transmitted tangential load, $\mathrm{N}$

$\mathrm{K}_{\mathrm{o}}$ is overload factor

$\mathrm{K}_{\mathrm{v}}$ is dynamic factor

$\mathrm{Ks}$ is size factor

$\mathrm{K}_{\mathrm{H}}$ is load distribution factor

$\mathrm{Z}_{\mathrm{R}}$ is surface condition factor for pitting resistance

$b$ is net width of narrowest gear, $\mathrm{mm}$

$\mathrm{Z}_{\mathrm{I}}$ is pitting resistance geometry factor

$d w_{1}$ is operating pitch diameter, $m m=2 \mathrm{a} / *(\mathrm{u}+1)$

$a$ is center distance, $\mathrm{mm}$

$u$ is gear ratio $>1$

$Z_{N}$ is stress cycle factor for pitting

$Z_{\mathrm{W}}$ is hardness ratio factor for pitting resistance

$\mathrm{S}_{\mathrm{H}}$ is safety factor for pitting resistance

$Y_{\Theta}$ is temperature factor

$\mathrm{Y}_{\mathrm{Z}}$ is reliability factor

$$
\begin{aligned}
& \sigma_{H}=Z_{E} \sqrt{F_{t} K_{o} K_{v} K_{s} \frac{K_{H}}{d_{W 1} b} \frac{Z_{R}}{Z_{I}}} \\
& \mathrm{~F}_{\mathrm{t}}=1.91 \times 10^{7} \mathrm{P} /\left(\mathrm{w}_{1} \mathrm{~d}_{\mathrm{w} 1}\right) \\
& \sigma_{H} \leq \frac{\sigma_{H P}}{S_{H}} \frac{Z_{N}}{Y_{\theta}} \frac{Z_{W}}{Y_{Z}} \\
& \sigma_{F}=F_{t} K_{o} K_{v} K_{s} \frac{1}{b m_{t}} \frac{K_{H} K_{B}}{Y_{J}} \\
& \sigma_{F} \leq \frac{\sigma_{F P} Y_{N}}{S_{F} Y_{\theta} Y_{Z}}
\end{aligned}
$$

According to the case study operating conditions and data, using AGMA standards [13, 14], the following parameters and constants were obtained and tabulated as shown in table (3):

Table (3) Obtained parameters and constants of gears

\begin{tabular}{|l|l|}
\hline Parameter & Value \\
\hline $\mathrm{P}$ & $315 \mathrm{kw}$ \\
\hline$w_{1}$ & $1450 \mathrm{rpm}$ \\
\hline$d w_{1}$ & $84.09 \mathrm{~mm}$ \\
\hline$m_{t}$ & $5.136 \mathrm{~mm}$ \\
\hline $\mathrm{B}$ & 85 \\
\hline $\mathrm{F}_{\mathrm{t}}$ & $49373 \mathrm{~N}$ \\
\hline $\mathrm{Z}_{\mathrm{E}}$ & $190\left[\mathrm{~N} / \mathrm{mm}^{2}\right]^{0.5}$ \\
\hline $\mathrm{Z}_{\mathrm{I}}$ & 0.25 \\
\hline $\mathrm{Z}_{\mathrm{N}}$ & 0.7 \\
\hline $\mathrm{Z}_{\mathrm{R}}$ & 1.1 \\
\hline $\mathrm{Z}_{\mathrm{W}}$ & 1 \\
\hline $\mathrm{Y}_{\mathrm{J}}$ & 0.48 \\
\hline $\mathrm{Y}_{\mathrm{N}}$ & 0.8 \\
\hline $\mathrm{Y}_{\mathrm{Z}}$ & 1.25 \\
\hline
\end{tabular}


$\mathrm{Y}_{\mathrm{J}}$ is bending strength geometry factor

$\sigma_{F}$ is bending stress, $\mathrm{N} / \mathrm{mm}^{2}$

$\sigma_{F P}$ is allowable bending stress, $\mathrm{N} / \mathrm{mm}^{2}$

$\mathrm{Y}_{\mathrm{N}}$ is stress cycle factor for bending

$\mathrm{S}_{\mathrm{F}}$ is safety factor for bending strength

$\mathrm{K}_{\mathrm{B}}$ is rim factor

$m_{t}$ is transverse metric module, $\mathrm{mm}$

$\mathrm{P}$ is transmitted power, $\mathrm{kw}$

$w_{1}$ is pinion speed, $\mathrm{rpm}$

\begin{tabular}{|l|l|}
\hline $\mathrm{Y}_{\Theta}$ & 1 \\
\hline $\mathrm{S}_{\mathrm{F}}$ & 1.2 \\
\hline $\mathrm{S}_{\mathrm{H}}$ & 1.2 \\
\hline $\mathrm{K}_{\mathrm{B}}$ & 1 \\
\hline $\mathrm{K}_{\mathrm{H}}$ & 1 \\
\hline $\mathrm{K}_{\mathrm{o}}$ & 1 \\
\hline $\mathrm{Ks}$ & 1.1 \\
\hline $\mathrm{K}_{\mathrm{v}}$ & 1.4 \\
\hline$\sigma_{F P}$ & $485 \mathrm{~N} / \mathrm{mm}^{2}$ \\
\hline$\sigma_{H P}$ & $1550 \mathrm{~N} / \mathrm{mm}^{2}$ \\
\hline
\end{tabular}

According to the above procedure and case study data, the analysis calculation results are:

- The contact stress: $\sigma_{H}=1300 \mathrm{~N} / \mathrm{mm}^{2}$

- The bending stress: $\sigma_{F}=400 \mathrm{~N} / \mathrm{mm}^{2}$

- The contact design stress term: $\quad \frac{\sigma_{H P}}{S_{H}} \frac{Z_{N}}{Y_{\theta}} \frac{Z_{W}}{Y_{Z}}=723 \mathrm{~N} / \mathrm{mm}^{2}$

- The bending design stress term: $\frac{\sigma_{F P} Y_{N}}{S_{F} Y_{\theta} Y_{Z}}=259 \mathrm{~N} / \mathrm{mm}^{2}$

\section{DISCUSSION OF RESULTS}

The above investigation results concerning material analysis, microhardness survey, microstructure and the stress analysis will be discussed in this section compared to; standards, designs and researches literatures results considering the case study operating conditions.

\subsection{The Material, Microhardness And Microstructure}

The material analysis confirmed suitable material as required, microhardness survey of the pinion had revealed that a carburizing case depth at the teeth was not confirming the recommended values of references $[17,18]$ because the depth equal $2.3 \mathrm{~mm}$ and it is much greater than the recommended suitable to the case data which causing the carburizing case is full hardened portion at the tip of the teeth. So, this portion miss its toughness and could not resist impact load. Also too much case depth makes the gear teeth more brittle with the tendency to shatter off the top of teeth [19]. All the above circumstances caused initiation of cracks and it was propagated until failure is occurred. This type of failure is classified as tooth bending fatigue failure [20].

The microstructure showed that the case microstructure consists of a tempered martensite and a small amount of the retained austenite which found to be adequate and confirmed the requirements.

\subsection{The Stress Analysis}

The results of the stress analysis had shown there were high level of contact and bending stress than the design values. The contact stress was $\sigma_{\mathrm{H}}=1300 \mathrm{~N} / \mathrm{mm}^{2}$ while the design value must within the value of $\frac{\sigma_{H P}}{S_{H}} \frac{Z_{N}}{Y_{\theta}} \frac{Z_{W}}{Y_{Z}}=723 \mathrm{~N} / \mathrm{mm}^{2}$.

Also the bending stress was $\sigma_{\mathrm{F}}=400 \mathrm{~N} / \mathrm{mm}^{2}$ while the bending design stress must be within the value of $\frac{\sigma_{F P} Y_{N}}{S_{F} Y_{\theta} Y_{Z}}=259$ $\mathrm{N} / \mathrm{mm}^{2}$.

Then there are two main problems in this case study; the big layer of carburizing case has to be carried out with the correct value and, the high level of; contact and fatigue stresses lead to the fast failure of the gears and must be investigated for solving it in the future. It is clear that high stresses come due to an error of design or an error of the gear box modification specially, it was used a single stage reduction while the gear casing has a multi stages axis as shown in figure (8). 


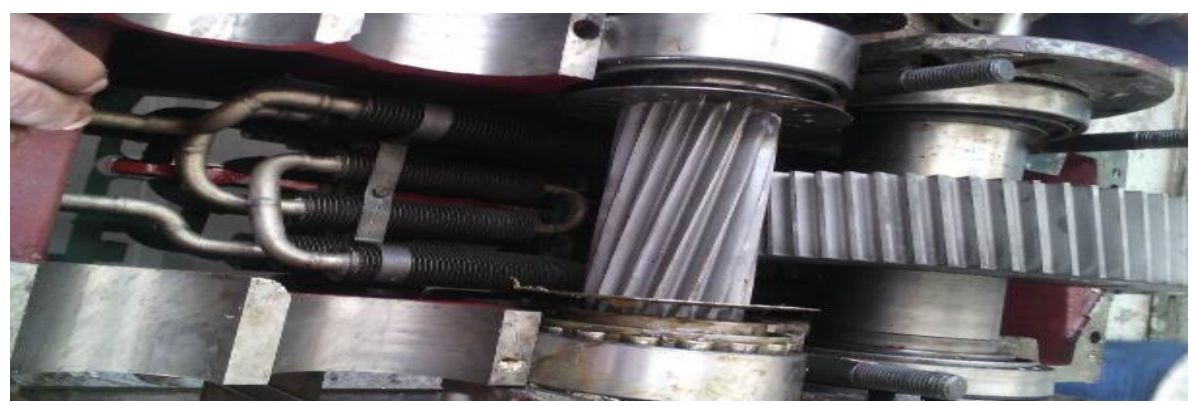

Fig. (8), a multi stage casing

\section{CONCLUSIONS}

The gears have mainly two problems; first is the big carburizing case depth which leads to brittle teeth tip and this could be changed to the suitable depth and, second is the high contact and bending stress levels and this required reanalysis of the gear box deign specially the gearbox casing has multi stage gearing instead of the used single stage gearing.

The next recommendations are drawn:

$\checkmark$ Carburizing depth 2.3 is very big which lead to brittleness and crack initiation lead to failure [21].

$\checkmark$ The dynamic factor $K_{v}$ and surface condition factor $Z_{R}$ are highly affected by the pitch variation accuracy so; the gear teeth must be grinded. AGMA2101-C95

$\checkmark$ The geometry factors $\mathrm{Y}_{\mathrm{J}}, \mathrm{Z}_{\mathrm{I}}$ must be improved AGMA 908 - B89

$\checkmark$ The profile displacement of gear larger than the pinion it is against the DIN 3960 recommendations [22].

$\checkmark$ The size factor could be improved by increasing the module [23].

$\checkmark$ Take care from increasing the pinion number of teeth because that has a disadvantage concerning the bending stress [24].

$\checkmark$ Redesign the gear box using the available reduction stages in the gearbox casing.

\section{REFERENCES}

[1] Luciana Sgarbi Rossino, Danilo Borges Villarino de Castro, Jeferson Aparecido Moreto, Cassius Olivio Figueiredo Terra Ruchert, Dirceu Spinelli, José Ricardo Tarpani "Surface Contact Fatigue Failure of a Case Hardened Pinion Shaft", Materials Research 2014; 17(3): 535-541.

[2] Aabed Saud Saber "Failure of an Oil Pump Bevel Gear", Journal of Failure Analysis and Prevention (2008) 8:419-425.

[3] V. E. Starzhinskii , Yu. L. Soliterman, A. M. Goman, and S. A. Osipenko "Forms of Damage to Gear Wheels: Typology and Recommendations on Prevention" - JOURNAL OF FRICTION AND WEAR Vol. 29 No. 5 - 2008

[4] Thomas Tobie, Peter Oster,Bernd-Robert Höhn" Systematic Investigations on the Influence of Case Depth on the Pitting and Bending Strength of Case Carburized Gears" - Gear Technology - July/August 2005

[5] Samroeng Netpu, Panya Srichandr "Failure Analysis of a Helical Gear" - The First TSME I nternational Conference on Mechanical Engineering 20-22 October, 2010, Ubon Ratchathani

[6] N. I. Yuruts and B. I. Aleksandrov "Fractographic study for tooth fracture for carburized helical gear wheels"- Metallovedenie i Termicheskaya Obrabotka Metallov No 8, pp 37-39, August, 1982.

[7] Shaji Koshy, Santosh G. Taji "Failure Analysis of a Gear" - International Conference on Recent Advances in Mechanical Engineering - ICRAME-2015 and International Journal of Engineering and Management Research (IJEMR) - pp 7-11- ISSN (ONLINE): 2250-0758, ISSN (PRINT): 2394-6962

[8] P. J. L. Fernandes and C. Mcduling "surface contact fatigue failures in gears"- Engineering Failure Ana(vsis, Vol. 4, No. 2, pp. 99 107, 1997

[9] Robert L. Errichello and Jane Muller "How to analyze gear failure" - POWER TRANSMISSION - MARCH 1994

[10] Hemanshu D. Joshi1, K. D. Kothari " Mode and cause of failure of a Bevel gear-A review " - International Journal of Advance Engineering and Research Development (IJAERD) Volume 1 Issue 2, March 2014, e-ISSN: 2348 - 4470 , print-ISSN:2348-6406

[11] Arvind Yadav " Different types Failure in gears-A Review" - International Journal of Science, Engineering and Technology Research (IJSETR)Volume 1, Issue 5, November 2012

[12] I, S. Kozlovskil, V. A. Olovyanishnikov, V. M. Zinehenko "Criteria for evaluating the quality and bases for rational selection, of carburized and nitrided steels, "Chemico-thermal Treatment - No. 3, pp. 2-9, March, 1981.

[13] ANSI/AGMA 2101-C95 (Metric Edition of ANSI/AGMA 2001--C95) "Fundamental Rating Factors and Calculation Methods for Involute Spur and Helical Gear Teeth"

[14] AGMA 908-B89 (Revision of AGMA 226.01) April 1989 (Reaffirmed August 1999) "Geometry Factors for Determining the Pitting Resistance and Bending Strength of Spur, Helical and Herringbone Gear Teeth"

[15] M. Berzal_E. G'omez V.V. Vera C. Barajas J. Caja "Auto-learning system for the calculation of spur and helical gears using ISO 6336" - 12th IFToMM World Congress, Besanc, on, June 18-21, 2007

[16] J.E. Shigley, L.D. Metchell, "MECHANICAL ENGINEERING DESIGN" - McGraw Hill Primis -eigth edition - 2008- ISBN: 0-390-76487-6

[17] ISO 6336-5-2003- "Calculation of load capacity of spur and helical gears".

[18] G. G. Vinokurov, S. P. Yakovleva, M. I. Vasil'eva, S. N. Makharova "Operational Failure of Tractor Gears", Russian Engineering Research, 2012 , Vol. 32 , No. 3, pp. 220-224.

[19] ASM International " Heat Treatment of Gears: A Practical Guide for Engineers" -2000 - ISBN: 0-87170-694-6, SAN: 204-7586.

[20] ASM HANDBOOK - VOLUME 11 - Failure Analysis and Prevention- ASM International - 2002

[21] R. I. Goher, B. S. Azzam and M. M. Abdrabou "Failure Analysis For Angle Head Spiral Gears"-

[22] DIN 3960 - 1980 " Concepts and parameters associated with cylindrical gears and cylindrical gear pairs with involute teeth"

[23] Bernd-Robert Höhn, Peter Oster and Christo Braykoff "Size and Material Influence on the Tooth Root, Pitting, Scuffing and Wear Load-Carrying Capacity of Fine-Module Gears" - Gear Technology - September 2011 - Conference on Gears, Technical University of Munich 2010

[24]Ishan Patel, Dr. M.S. Murthy "Comparison of bending stresses for different number of teeth of spur gear obtained using MATLAB Simulink with AGMA and ANSYS” - International Journal of Engineering Trends and Technology (IJETT) - Volume4 Issue7- July 2013 